\title{
UNA MANO DE NEGRO
}

El horror siempre ha llezido una máscara o un rostro, y siempre ha temido un nombre: Satän, Gorgona, Leviatán, Aisha Kandisha.

Francoise Duvignaud

Edmundo Motta Zamalloa'

\section{INTRODUCCIÓN}

El negro no es sólo el color de un rostro, es también un estereotipo social y ético, el personaje engreido del humor y la caricatura, tan familiar en la literatura grotesca y de la otra. Ha sido preferido como referente del horror, acaso porque el negro se asocia a la oscuridad y a las tinieblas. Muchas veces el negro fue tomado como el equivalente del mal, o quien mejor personifica al esclavo. La acción oculta, la maniobra indeseada que se consuma en un hecho es automáticamente atribuida a una mano negra, aunque sean blancos, claro está, los protagonistas de la intriga. El rito o la magia orientados a causar daño acaban asociándose al negro. La noche es negra, la muerte también.

Aunque desagrade a mucha gente, nadie puede admitir a discusión la humanidad de quien lleva el rostro negro, tan igual que el blanco, el amarillo o el cobrizo, o de las muchas variantes que se han cruzado en la sociedad. Tal vez por compensación, negra o negro son conversos adjetivos para designar a quien ocupa un lugar en el corazón. No es usual la expresión "mi blanca», en cambio es frecuente oir «mi negra» o "negrita», aunque la tal no sea mulata.

Cuestión de color, nada más. Pero el juego de los extremos blanco/negro ha terminado por cualificar las cosas, las personas, las acciones. Ha definido una historia, tiene un continente, una región geográfica, un barrio propio, un equipo de fútbol, amen de una riquisima y compleja cultura. La alegria explosiva es negra, negra también la profunda tristeza. La maldad es de color negro ¿De qué color es el bien? Si uno se echa a pensar en el tipo de acción mágica

1. Antropólogo. destinada a propiciar el bienestar de una persona, se sabe que estamos hablando de magia blanca.

El Titulo de lo que viene adelante es historia conocida por los desocupados lectores de Rómulo Cúneo Vidal, que trata sobre el crimen cometido por Eleazar -un "mulato consentido", de diecisiete años de edad, hijo de una esclava negra-, en contra de su benefactora Ana Yañez de Montenegro. Quedé tan impresionado, probablemente como el propio Cúneo, cuando encontró las anotaciones marginales, hechas de puño y letra, por el párroco Miguel Cornejo, en el libro de defunciones de Sama del siglo xviii reconstruido 110 años después con la versión oral de una antigua sameña-, que no me contuve de hacer una repentina asociación con una reciente superstición que ha provocado pánico en sectores populares tacneños. La historia lleva por título «una mano de difunto...», y la supertición fue designada simplemente como "la mano negra». El primero ocurrió en el siglo xviii y el segundo en 1990, pocos meses después del reajuste económico que conmocionó al pais.

La asociación fue posible porque el difunto de la historia era negro, de modo que podría especificarlo con una ligera variación y dejarlo de esta manera:»una mano de negro...», sin que esta osadia pudiese traicionar en lo mínimo el contenido del relato. Terminé entonces planteando una sospecha:¿pudo "una mano de negro» atravezar el tiempo y convertirse en "la mano negra»? La idea fue tomando cuerpo en la medida que se podian asociar historia y supertición, realidad y fantasia, donde la parte de la historia puede servir como fuente de lo que vendrá, "andando el tiempo», convertido en superstición o fantasía y que, una vez perdido el vínculo, es mucho más fácil atribuir a la febril inventitividad de las culturas ágrafas y tradicionales, con denotado menosprecio por aquello que alguna vez fue historia. Llamo historia al hecho ocurrido que, en el caso de 
nuestro interés, terminó por instalarse en el inconciente colectivo del que aflora a la superficie de la cultura bajo ciertas condiciones de cáracter existencial.

En consecuencia, me ocuparé sucesivamente del negro a quien le cortaron la mano en el dieciocho y luego de esa mano que, emergiendo de las cloacas de 1990, aterrorizó a niños y adolescentes, y causó muertes que no se enterraron.

\section{SAMA EN EL SIGLO XVIII}

Corría el año de 1776. El valle de Sama retenía aún el prestigio que tuvo en otras épocas por la fertilidad de sus tierras y la abundancia de agua que mantenia permanentemente abastecida a sus cultivos. Era preferida por los pobladores de los altos de Sama, quienes la empleaban como ruta forrajera hacia las estacionales lomas que bordean el litoral. Por aquellos tiempos las lomas eran, por decir lo menos, pródigas en pasto.

Sin embargo, dieciocho años después, el Intendente Antonio Alvarez y Jimenez, a su paso por el valle, habria de comprobar que gran parte de las tierras del valle permanecian sin cultivo alguno por falta de agua debido a que bañaba «dicho valle un pobre río»; pero que a pesar de ello el paisaje conservaba algo de sosiego que trasmitia al espiritu del caminante (1).

El propio nombre de derivación quehua y aymara denotaba ese significado. Sama era el «lugar de descanso» para los indigenas, sea porque constituia el punto de paraje en la travesia de intercambio de productos de altura con los del valle y los del litoral ( pescado, conchales, moluscos y guano de isla); sea también porque era un paso cuya salubridad del clima ayudaba a permanecer en el lugar en los periodos en que aprovechaban los pastizales de las lomas vecinas, particularmente durante las temporadas húmedas del año. No podría ofrecer mejores ventajas en la colonia a la arrieria, pues desde Sama se despachaban aji, algodón, legumbres, plátanos, granadas y granadillas; pero especialmente el alcohol de $\mathbf{4 0}$ grados hacia la Villa de Potosí, la Paz y Oruro, otorgándole un movimiento comercial muy dinámico hasta el momento de decadencia de la mineria. Especial prestigio tuvo la hacienda de cañaveral de B.J. Rospigliosi y otras que dedicaban sus tierras al cultivo de este producto para emplearla en la elaboración de aguardiente. Cuando se produjo la visita del Intendente Alvarez y Jimenez la producción de caña había entrado en franco deterioro (2).
Dividida en Sama de Arriba y Sama de Abajo, cuyos asientos eran Yalata y Tomasiri, respectivamente, tuvieron dos capillas, una para cada sector, pertenecientes ambos a la Doctrina de Sama, de cuya conducción, en la tarea de evangelizar a los indios, se encargaban los sacerdotes dominicos, desde el año de 1565 , convertido a partir de entonces en cabeza de doctrina de los pueblos ubicados valle arriba, incluyendo las serranias de Tarata, y por el norte a Locumba (3).

Para la administración de seguridad, justicia y policia, se había constituido en Sama tres compañias completas -primera, segunda y cuarta- del Tercer Escuadrón, dependiente a su vez del Regimiento de Dragones del Partido de Tacna. A cargo de la primera compañía estaba el sargento Lucas Ibarra; la segunda comandaba el capitán don José Antonio Tagle y Bracho, y el teniente don Felipe Arguedas tenia bajo su mando a la cuarta compañia, todas bien dotadas y abastecidas. Sus soldados andaban montados a caballo, cuya crianza, dicho sea de paso, era una dedicación predilecta por las exigencias de la arriería (4). Con tal recurso, al que había que añadir el permanente estado de alerta por las inseguridades que trasmitía el acoso de los puertos por los piratas, los soldados estaban siempre a punto y en cosa de sesenta horas podian estar en condiciones de "ponerse a boca» del puerto de Arica.

Por lo que toca a sus gentes, de acuerdo con el Padroncillo que consignó el Intendente, hacian un total de 851 almas entre españoles (166), mestizos (281), indios (114), mulatos (281) y negros (9), dedicados a dos actividades caracteristicas del valle de fines del siglo xviii: la labranza y la arrieria. Es posible imaginar una convivencia marcada por las tensiones étnicas propias de la colonia, las que se expresaban en permanentes huídas de las casashacienda, abuso de los débiles y crímenes.

\section{LA VIDA DE UN NEGRO NO VALE NADA}

Apenas nacido en 1749, Eleazar tuvo el infortunio de ser abandonado por su progenitora en la puerta de la casa hacienda de los Osorio Yañez de Montenegro. A saber por la historia contada por Cuneo, la buena doña Ana recogió al niño del desamparo y le dió trato y crianza como a cualquiera de sus cuatro hijos, dos de ellas mujeres que vivian en la propia hacienda y los varones, que al momento del crimen, habian recalado en la virreinal ciudad de Lima donde estudiaban en el Seminario de San Carlos. 
Es posible que la madre adoptante hiciera alimentar al niño con pecho de alquiler o fue encargada, como era costumbre por entonces, a alguna de sus criadas o esclavas. Un mulato consentido gozaba de ciertas concesiones que no estaban permitidas a los esclavos y podia, por tanto, sentirse como un miembro de la familia, empezando porque no dormia en el galpón destinado a la servidumbre. Este privilegio no lo exoneraba, sin embargo, de la obediencia rígida a la que estaba obligado. Podia marchar junto a su ama, como ocurria con Eleazar, convertido en leal compañero en la inspección de labores agricolas, y montado a caballo tanto como su ama.Pero un prohijado no es un hijo, y mucho menos si su identidad correspondía a la clase de negros y esclavos.Por más esfuerzos que desplegaran para desarraigarlo y por mucho empeño interior que pusiera Eleazar para reforzar su autoestima, en un estatus distinto que lo aproximaba a la familia adoptante. Eleazar vivía poseido por un espíritu trágico en permanente contraste cotidiano. «Me recogiste (...) a la puerta de tu casa, del fango del arroyo, donde me habia abandonado una madre sin entrañas...¿ ¿Por qué lo hiciste?...¿Por qué no me dejaste morir en él?..¿Por qué no me condenaste a la vida del paria en el galpón de tus restantes esclavos?...¿ ¿Por qué no me dejaste negro?...¿ ¿Por qué transmitiste a mi ser, sentimientos de blanco?...»(5).

Su condición de consentido, pese al drama interior que sobrellevaba, le otorgaba a Eleazar una cierta perspectiva para hacer conciencia de la clase de vida que tenian sus congéneres de raza condenada a una existencia cerrada sin escapatoria posible.Si bien era cierto que una madre desnaturalizada lo había librado de la vida de paria, su condición actual era vulnerable, y el camino de retorno a la identidad social de origen podria ser cuestión de tiempo o del azar. Consumado el crimen de su benefactora, la madre que cogió la posta de la primera, en la tarea de concretar el desarraigo, Eleazar, instalado ya, abruptamente, en la situación de esclavo y paria,expresó con firmeza inequivoca ante los miembros del tribunal de justicia: «Hubiera querido alejarme para siempre de la hacienda, pero ¿a dónde ir que no diesen conmigo y me trajesen maniatado a poder de mis amos a quienes aborrecí desde aquél momento, y a cuyo lado comprendi que no hubiera podido vivir un solo día más?...¿Qué hubiesen hecho éstos conmigo?...¿ ¿No soy carne de esclavitud?... y ¿hay, acaso, piedad para con los de mi condición?...»(6).

\section{SEÑORA DE TUL BLANCA}

Los esposos Osorio y Yañez de Montenegro constituian esa suerte de «bondadosos esposos (que) recogieron diecisiete años atrás a la puerta de su noble hogar, y a quien criaran libre y consentido poco menos que como a un hijo...» (7).

Doña Ana Yañez de Montenegro de Osorio, llamada señora en la mejor acepción que podía otorgársele al termino, denotaba en la época a la dama de respeto y abolengo, en cuyos ascendientes se podia registrar a lo más graneado de la gente española, no tanto por el origen español como por la nobleza misma de sangre. Doña Ana Yañez de Montenegro era descendiente de don Jerónimo Gascón Yañez de Montenegro, cabeza de una de las 40 familias primordiales enviados a poblar Arica por el Rey don Felipe II en 1559. Don Jerónimo Gascón era oriundo de Galicia; su padre estuvo emparentado con los Yañez Pinzón de Palos de Moguer, compañeros de Cristóbal Colón en el descubrimiento de Nuevo Mundo, deudos, a su vez, aunque lejanos, del conde Yañez del Romancero, primo hermano del Cid Campeador. A su muerte en 1627, don Jerónimo Gascón dejó una prole de siete hijos que se dispersaron por el territorio del sur haciéndose de propiedades. Uno de sus descendientes, Luis, compró en 1651, en 500 pesos, tierras de lqui (Ite) en las lomas del Morro de Sama, y por la misma fecha obtuvo en arriendo la hacienda de Tomasiri por 250 pesos anuales (8). Además de estas tierras, los Yañez de Montenegro registraron su apellido como titulares de otras tantas propiedades en Calana,Locumba, Arica y la lejana y codiciada Villa de Potosí.

No sólo tierras transformadas en haciendas. Una hacienda colonial, cuyos dueños se reclamaban tributarios de la república de españoles, incorporaba una cantidad de mano de obra constituida por indios y esclavos en servicio permanente, sobre los cuales pesaba jurídicamente la propiedad de los amos. La hacienda Tomasiri, cuya extensión abarcaba desde Sama Vieja hasta los limites de Buena Vista, requería de la presencia permanente y estacional de una servidumbre que cubriese las necesidades de la agricultura.

\section{INTEGRACIÓN CON MARGINACIÓN}

Señores, indios ligados a la hacienda, criados y esclavos, formaban parte de una suerte de mancomunidad social en la que un sustrato de convencionalismo condujo a los pobres a compartir intereses, recogida en derechos y obligaciones, que 
atraian, cuando menos, la mirada condescendiente de los señores ante Dios, el rey y los hombres (9). Destacaba en todo tipo de relación la necesidad de la jerarquía de clase establecida, inspirando en los sometidos conformidad material con su posición social. Los miserables -indios y esclavos- debian desarrollar una personalidad social absolutamente disminuida que les permitiera pensar y actuar con algún sentido liberador y de sana autoestima. Los señores estimulaban, al menos en apariencia, las aspiraciones de mejora de los miserables a través del concubinato o el matrimonio ventajosos, y, como en el caso de Eleazar, cierta libertad graciosa(10).

¿Hasta que punto fue integrado al estatus de Ia familia adoptante? Dicho de otra manera, ¿consiguió la familia Osorio Yañez de Montenegro aislar a Eleazar del resto de criados y esclavos que formaban el entomo de la hacienda? ¿Pudo ser blanco en apariencia lo que era negro en la realidad y en su naturaleza? Todo parece indicar que Eleazar creció sin haber sido plenamente integrado a la familia de los Osorio Yañez de Montenegro, si bien fue criado en la categoría de los morenitos consentidos -mulatos, cuarterones y sacalaguas-, en lugar de pasar la vida de paria confinado al galpón de los restantes esclavos y criados, mantuvo intacto su conciencia de mulato, marginal y fuertemente ligado a su condición de origen y raza. Al mismo tiempo pesaba en èl los afanes de la familia, y no sòlo de doña Ana, transmitirle a su espíritu ideas y sentimientos que correspondiesen al estatus de la raza adoptante.Eleazar vivía simultaneamente en los dos mundos absorviendo y acumulando sus pasiones y conflictos, llevando una existencia que no podia sustraerse al juego pendular de la apariencia y la realidad, y cuyo desenlace se develará trágicamente durante el encuentro entre el victimario y su víctima. Una simple ilusión de sentirse madre de alguien que no podía ser su hijo se vino abajo a la hora en que doña Ana Yañez de Montenegro tuvo que enfrentar al joven mulato quien, por su parte, redescubría abruptamente su condición no de mulato, sino de negro y esclavo. Y como esclavo sólo podía acceder para consumar el crimen a instrumentos que formaban parte de su itinerario: machete de cortar caña, hacha de tronchar árboles, o cuchillo de refalar menesteres en la cocina. Eleazar eligió el familiar instrumento de cocina.

\section{CRIMEN Y CASTIGO}

Pero ¿Cuál fue el verdadero motivo del crimen? El relato es muy escueto en este punto y sólo menciona una reconvención hecha por la víctima que hirió a Eleazar,por parecerle injusto. Un motivo que, por lo demás, podia haber sido cotidiano en el escenario de una hacienda:» ¿por que no me dejaste negro? ¿por que transmitiste a mi ser, sentimientos de blanco? me has reñido injustamente...me has llamado negro, y por ello debes morir» (11). ¿Hubo algo más grave que una reconvención, por ejemplo un robo, una desobediencia atroz que podia haber puesto en peligro la integridad de bienes de la hacienda, y que fue omitido en el relato? ¿O, tal vez, una desavenencia afectiva, negada a ser presentada en la historia? Cualquier hecho, sujeto a especulaciòn, pudo haber sido el desencadenante, a la que, por cierto, ayudó el contexto social y moral, donde el juego entre lo real y lo aparente, puede resultar peligroso cuando se acumula en el tiempo, después del cual, un sencillo denuesto es capaz de precipitar una tragedia. Esta fuente es la que aparentemente genera, conforme al texto, el crimen de Ana Yañez de Montenegro. La víctima "no alcanzaba a comprender que suerte de falla del sentido moral, ni que inconcebible extravio habían podido armar la mano de su innoble asesino" (12).

"La señora mi ama me riñó con sobrada dureza por una contestación que le di al escuchar una reconvención que no crei merecer...me llamó negro...Lloré, no se si de pena, o bien de rabia durante toda una noche..." (13). Una razón suficiente, aunque difícil de admitir dentro del cuadro de costumbres de la época. Para el espíritu atormentado de Eleazar "negro" implicaba devolverlo al galpón de los parias esclavos.

La noche que ocurrió el crimen doña Ana Yañez de Montenegro intentaba conciliar el sueño, tras haberse librado de otros intentos de homicidio en el día, los que no habia advertido. Aquí llama la atención otro hecho revelador: el homicidio no puede consumarse de dia.Eleazar debe buscar la oscuridad y esperar que su víctima se duerma, pues la mirada bondadosa de los ojos de su benefactora es capaz de desarmarlo. Aun cuando se está consumando el crimen Eleazar es presa de una febril lucha entre el bien -que creia percibir en su ama- y el mal que se apoderaba de su cuerpo y alma. Creía sentir la fuerza de una voz poderosa venida desde las profundidades de su ser y que lo impulsaba a asestar el puñal, como dejó dicho a los honorables miembros del tribunal de justicia: "el MALO... se apoderó de mi", pues escuchaba su siniestro mandamiento "!mata!" "!mata!". Sin duda, ese otro que habla en nosotros como reza la crítica lacaniana a la adaptación a la realidad- era, socialmente hablando, los otros, "su 
raza", en atávica espera de un acto reivindicativo, y personificado en el "maldito" que impulsaba a Eleazar a cometer el crimen.

La escena del crimen fue presentido por el esposo de la víctima, Ponciano Osorio, quien se encontraba de visita en la ciudad de Arica, reflejado en el cuerpo del cáliz de oro que elevaba durante la eucaristia, en la misa que celebraba su hermano. Una horrenda visión que venía a confirmar sus pesadillas de noches continuas que le habian erizado los nervios y lo mantenía ensimismado imaginando una próxima tragedia en su hogar. Su sorpresa fue mayor y su preocupación más profunda cuando el meditabundo sacerdote dijo a su vez haber visto aquella misma visión reflejado en el cáliz. Las imágenes no eran difusas, muy al contrario, podian reconocer con toda nitidez a su esposa Ana y a su homicida Eleazar.

De regreso en Tacna, los mayordomos de la hacienda le revelaron la fatalidad ocurrida en su ausencia: su esposa habia sido asesinada la noche anterior por Eleazar. El pueblo estaba conmocionado con la tragedia. Y Eleazar que no pudo o no habia necesitado huir, estaba detenido y resguardado en el Escuadrón policial.

Su expresión era serena, sin embargo; tal vez porque ya habia conseguido liberar al «malo «y estaba dispuesto a enfrentar a los jueces y entregarse a la muerte. Si había algo de nuevo en él, era que se sentia distinto al Eleazar que todos conocieron. No necesitó negar la caridad con que lo habian criado ni la calidad de buena persona que era doña Ana Yañez de Montenegro. Entregó también en sinceras lágrimas su profundo arrepentimiento sin esperar a cambio que lo perdonasen. No pidió nada para si y guardó silencio.

El pueblo se habia concentrado en la plaza; delante del gentío que llenaba el perimetro, al centro de la explanada, un brioso caballo aguardaba mansamente bajo el peso de un nervioso y sombrio soldado. Arrastrado por aquel caballo que amenazaba desbocarse llevando tras de sí una desacostumbrada carga sujeta por cuerdas de cuero, Eleazar se dejó llevar dejando tras su cuerpo una estela de polvo. Fue ahorcado enseguida en el centro de la Plaza Mayor. Su brazo homicida fue cortado y colocado "para ejemplo y excecración sempiternos» en una jaula de hierro, puesta al final de un poste de madera que se irguió en la Plaza de Buena Vista, muy cerca de la hacienda Tomasiri y frente a la parroquia.

\section{EL SABOR DE MENTA}

La mano disecada colgaba en lo alto del poste durante décadas como una medida de escarmiento. Varias generaciones la vieron. Los primeros años, aquella mano habia pertenecido sólo a un negro maldito y asesino; después el tiempo fue borrando poco a poco ese juicio popular y sustituyéndola por otra menos cruel que señalaba a un negro ingrato que se habia arrepentido en la hora de la muerte, hasta que las generaciones que vivian alejadas del tiempo en que había ocurrido el homicidio sólo encontraban tras el brazo a un triste mulato, abandonado por su propia madre al nacer en la puerta de una hacienda, criado como esclavo que un dia perdió la razón y cometió el acto que contaban los padres y abuelos. La historia de aquél brazo no habia cambiado en lo mínimo, pero si el juicio de las gentes.

Es posible que los fines de escarmiento para los que fue expuesto la mano del mulato Eleazar surtiera sus efectos, no tanto porque no se hayan vuelto a repetir homicidios semejantes, de los que no tenemos historia criminalística, sino mas bien que la historia de Eleazar se haya integrado a advertencias morales y hasta medidas coercitivas para encausar una orden de los padres a los hijos. En lo que respecta a lo primero, la noción de castigo jugaba un papel que se revelaba por si mismo sin necesidad de mayores explicaciones, pues bastaba referir la historia. En cuanto al aspecto coercitivo, la imaginación popular tuvo que haber convertido antes la mano de Eleazar en estereotipo fantástico capaz de actuar desde la soledad, la nocturnidad y el silencio del campo sobre la conducta de los habitantes de Sama. Junto a las historias de "la cabeza que rueda», "los arrieros fantasmas», «las almas que penan», «el Padre sin cabeza», tan populares entre las gentes del campo y la ciudad de Tacna, se agregó, con el correr de los años, la de "la mano negra».

\section{SUBTERRÁNEO DE LA MANO NEGRA}

"Los periodos de convulsión e inseguridad social han activado los temores más profundos y atávicos (pérdida de identidad, sumisión, mutilación, muerte) del ser humano" -dicen Gubern y Prat(14)que han encontrado su puntual reproducción en el escenario cotidiano.

Puesta en marcha el choque económico de 1990, que tuvo efectos muy severos en la vida de la población, reduciendo a los sectores menos pudientes a niveles críticos de subsistencia, la sociedad en su conjunto se encontraba muy sensibilizada como para generar una autopercepción comparable sólo con la mutilación del cuerpo.El escenario se habia tornado propicio para que emergieran desde las reconditeces 
del inconsciente historias y estereotipos fantasmales que, de pronto empezaron a circular causando terror y buscando víctimas en los sectores más sensibles. Los "sacaojos" recorrian las calles de Lima, los "phistacos» volvian a las andadas en Ayacucho y la sierra sur,y «la mano negra» cobraba lo suyo en Tacna.

De acuerdo con las versiones, dispersas y no pocas veces contradictorias, propaladas con singular controversia por los medios de comunicación, se trataba de una innominada mano negra que rondaba por escuelas y colegios, y por los pueblos jóvenes, aterrorizando especialmente a niños. Algunas de esas versiones, no comprobadas por cierto, aseguraban inclusive que la mano negra causó algunas muertes.

Mencionemos la patética descripción de Victor (45 años de edad, del pueblo joven de La Natividad):la mano negra es un personaje diabólico que tiene el cuerpo en forma de un brazo humano, de color negro; lleva los ojos, nariz y boca en la palma, y en el dorso tiene cabellos más o menos largos y en completo desorden. Emerge de alguna cloaca a través del water y camina dando pequeños saltos por la pared cerrando y abriendo el puño. En su trayectoria deja manchas de sangre y en ocasiones puede saltar al cuerpo de su víctima.Su sola presencia de esperpenta figura puede ocasionar la muerte.De preferencia suele mostrarse a las personas de carácter débil, por lo general niños y adolescentes, pero rehuye a las personas menos crédulas y mayores de edad.

Sería ocioso preguntarle a Víctor, o a cualquier otro portador de una versión coincidente 0 distinta, pero que se relaciona con el mismo monstruo, si tiene en la memoria algo que recuerde a la historia del mulato sameño; pregunta que, por otro lado, dejaría de tener sentido. Con toda seguridad la desconoce, tanto como los propios sameños de hoy

\section{NOTAS Y REFERENCIAS BIBLIOGRÁFICAS}

(1) Barriga, Victor M; 1948 :Memorias para la historia de Arequipa, T.III ;pgs.154-155. Sama pertenece a la jurisdicción del actual distrito de Inclán, provincia y departamento de Tacna, ubicado a $30 \mathrm{~km}$, hacia el norte de la ciudad del Caplina, en el valle del mismo nombre

(2) Ibidem

(3) Ibidem

(4)Zora Carbajal,F; 1969 :Tacna, historia y folklore. Pgs.31-33

(5) Cúneo Vidal,Rómulo;1977 ;"Una mano de difunto...", en Historia de los cacicazgos del Sur del Perú, T.V.,pgs.252-258.

(6) Ibidem

(7) Ibidem que viven en Buena Vista, a un paso del lugar donde estuvo el poste conteniendo la jaula de metal con el brazo disecado de Eleazar. El negro don Exito (vaya el nombre lírico), con sus setenta años a cuestas, que vive frente al viejo templo de Buena Vista, y sale todos los dias por la misma puerta que daba directamente a la jaula de escarmiento, se sorprende que en su pequeño y telúrico pueblo hubiese ocurrido en el pasado una historia semejante.

Los acontencimientos que han calado profundamente en la experiencia humana suelen ser modelados por los avatares de la metamorfosis. Pierden en el camino su original sentido y adquieren otros significados. La mano del mulato Eleazar colocada en una esquina de la plaza pública, no perseguía otro propósito que el escarmiento para un grupo social que osara romper los limites de la obediencia y sumisión. En cambio la mano negra, aparte de provocar horror, puede responder a otras demandas de la mente inquisitiva. Para nuestro amigo Victor, el monstruo de 1990, podria ser la incorporación del espiritu de alguien que ha muerto pero sin morirse por completo, que se encuentra en esa existencia indefinible de ser y no ser, y de no poder fijar un espacio en la dimensión conocida pena como quien paga una condena. En el ideario metafísico popular, puede ser tomado como un indicador que anticipa lo inevitable, merced al cual el alma de la persona, que acaba de ser convocada por la providencia para abandonar este valle de lágrimas, recorre-convertido en una mano negra- los derroteros que transitó en vida tratando de eliminar todo vestigio de su existencia. Convertido en una mano negra, en un animal o simplemente sin sufrir metamorfosis alguna, se deja ver, oir su voz, de modo que se perciba su presencia, se lo sienta y tema; tanto como se teme el fatal augurio en el canto lastimero de un ave o en la forma extraña de un remolino.

(8) Cúneo Vidal,Rómulo;1978 :Diccionario Histórico Biográfico del sur del Perú.

(9) Tord, Javier y Lazo, Carlos; 1980: Movimiento y sociedad en el Perú colonial; en Historia del Perú,T.V.,Edit.Juan Mejia Baca; pgs.81-83.

(10) Ibidem: pg.84.

(11) Cúneo Vidal, R: Una mano de difunto...

(12) Ibidem

(13) Ibidem

(14) Gubern,Román y Pratt,Joan;1979:Las raices del miedo; pg.12. 


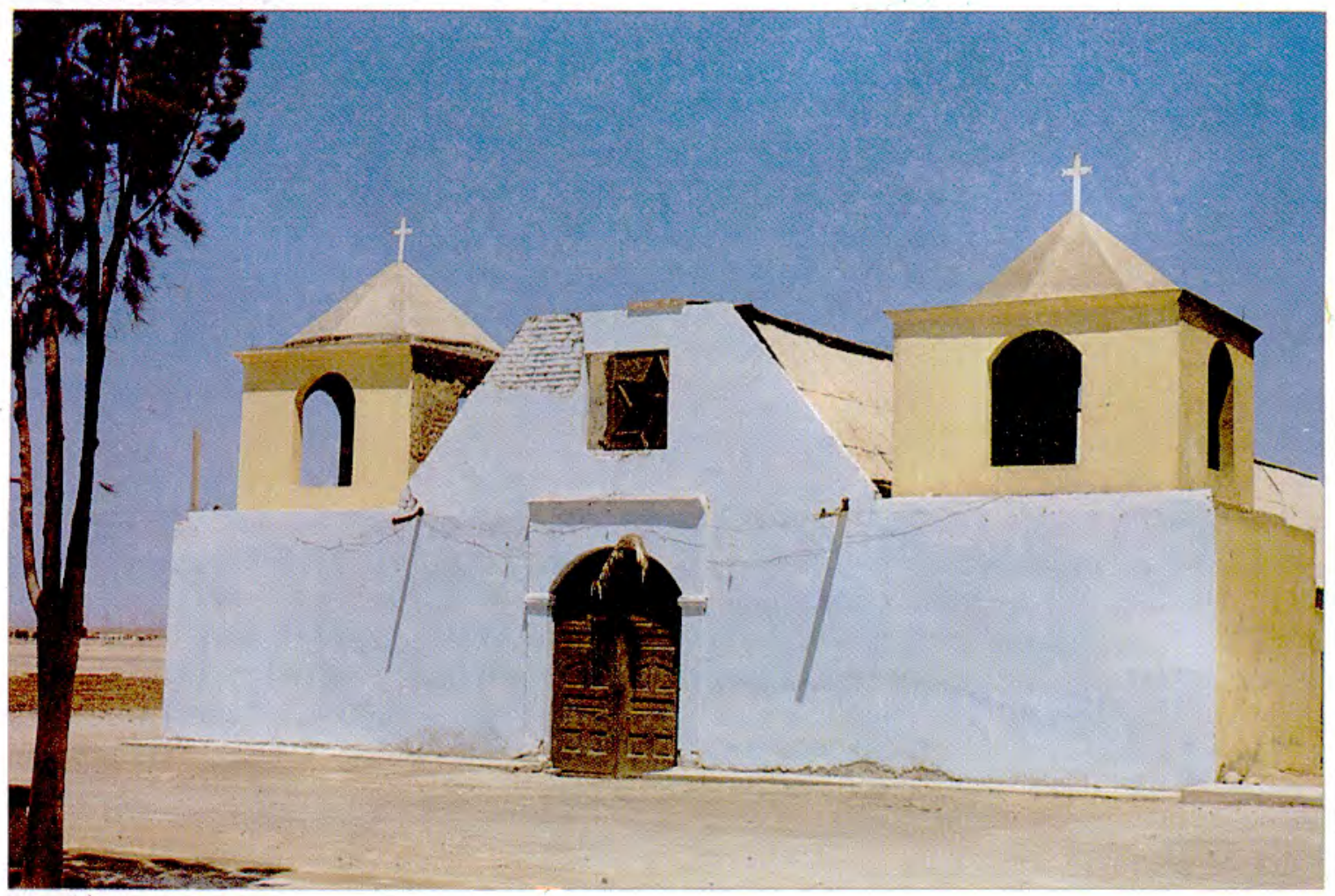

Templo de Buena Vista, ocupa el escenario donde se exhibió la mano de Eleazar para escarmiento del pueblo.

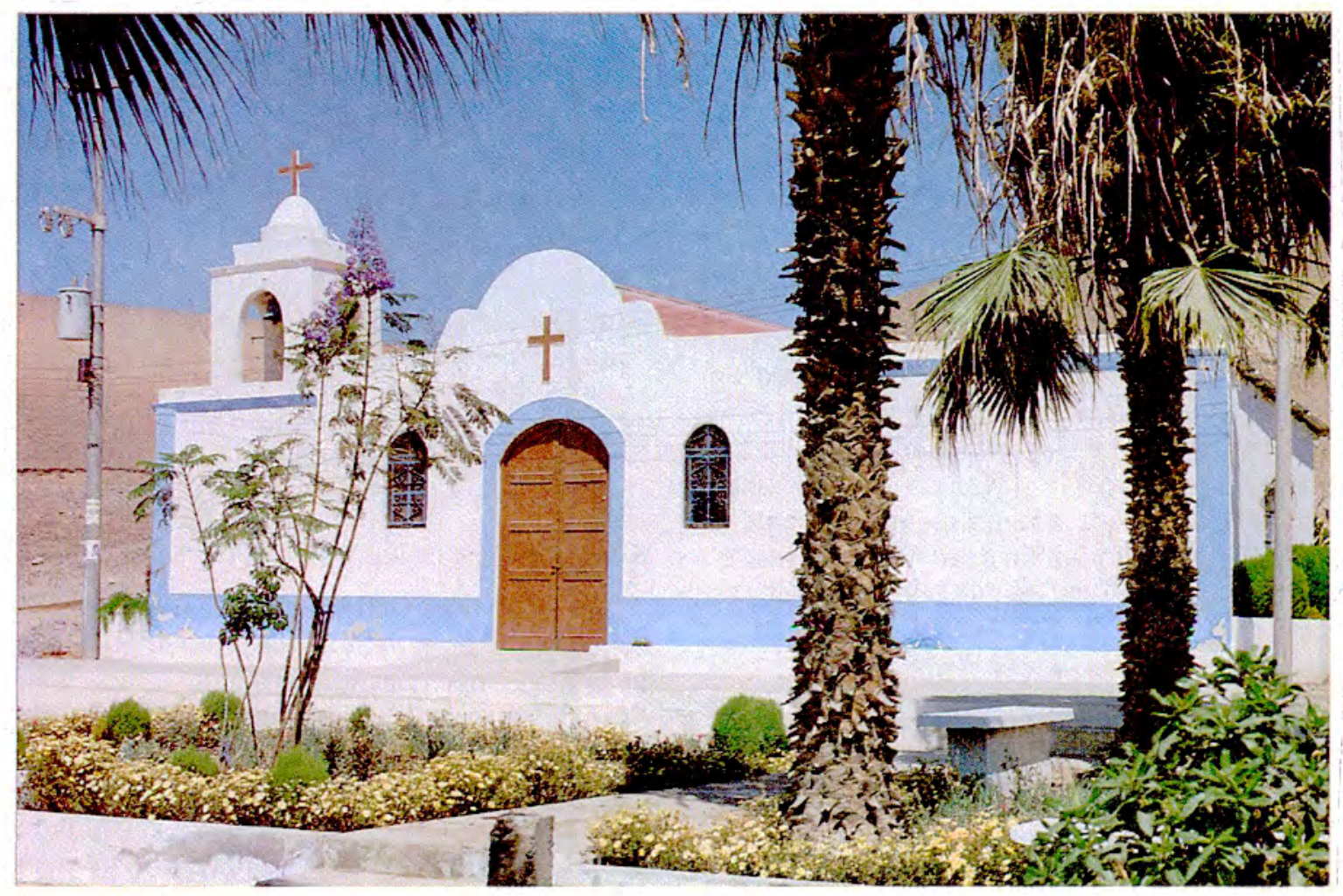

Actual Templo de Alto del Rayo, en Sama la Vieja, cabeza de Doctrina del Valle y sus serranías en el S. XVIII. (Fotos: Hemz) 